\title{
Hot Deformation Behavior and Dynamic Recrystallization Characteristics in a Low-Alloy High-Strength Ni-Cr-Mo-V Steel
}

\author{
Chuan $\mathrm{Wu}^{1} \cdot$ Shuang $\mathrm{Han}^{2}$ \\ Received: 21 November 2017/Revised: 26 January 2018/Published online: 18 April 2018 \\ (C) The Chinese Society for Metals and Springer-Verlag GmbH Germany, part of Springer Nature 2018
}

\begin{abstract}
This study presented a quantitative investigation of deformation behavior and dynamic recrystallization of low-alloy highstrength $\mathrm{Ni}-\mathrm{Cr}-\mathrm{Mo}-\mathrm{V}$ steels during hot deformation. A series of isothermal compression experiments were performed at temperatures ranging from 800 to $1200{ }^{\circ} \mathrm{C}$ and strain rates from 0.01 to $10 \mathrm{~s}^{-1}$ with a height reduction of $60 \%$. A complete Arrhenius constitutive model and processing maps were developed. The results showed that the constitutive model had the ability to predict the flow stress with an average absolute relative error of $<5.7 \%$. The processing maps constructed at strains of $0.2,0.4$, and 0.8 showed that flow instability was prone to occur at higher strain. Dynamic recrystallization tended to take place at higher temperatures $\left(900-1200{ }^{\circ} \mathrm{C}\right)$ and lower strain rates $\left(0.01-1 \mathrm{~s}^{-1}\right)$. The critical strain for the onset of dynamic recrystallization was determined, and a kinetics model was developed. The predicted results for recrystallization volume fraction and flow stress were compared with the experimental data, which indicated that the model was accurate and reliable.
\end{abstract}

Keywords Deformation behavior - Dynamic recrystallization - Constitutive equation - Processing map - Critical strain · Recrystallization kinetics

\section{Introduction}

In recent years, low-alloy high-strength steels have been widely used in the fields of ship building, the drilling platforms of offshore oil and gas, and aerospace manufacture, due to their mechanical properties of high strength with good toughness and ductility without the occurrence of fracture and failure [1]. In these fields, many requirements are necessary to ensure the proper microstructures, excellent properties, and good dimensional stability [2]. To satisfy these requirements, the materials have to be subjected to complicated hot deformation and microstructural

Available online at http://link.springer.com/journal/40195.

Chuan Wu

zjkwuchuan@126.com

1 National-Local Joint Engineering Laboratory of Intelligent Manufacturing Oriented Automobile Die \& Mould, College of Mechanical Engineering, Tianjin University of Technology and Education, Tianjin 300222, China

2 College of Mechanical Engineering, Yanshan University, Qinhuangdao 066004, China evolution. On the one hand, a given hot deformation processing route yields a particular metallurgical phenomenon (microstructural evolution); on the other hand, the microstructural evolution during the hot deformation process, in turn, influences the mechanical properties of the material [3]. Thus, it is significant for designers of materialforming processes to understand hot deformation mechanisms and microstructural evolution of materials [4-5].

Hot deformation is an effective method for shaping metals. To precisely simulate the deformation process, many constitutive models have been proposed. These can be divided into phenomenological, physical-based, and artificial neural network models [6]. Among these, the Arrhenius equation is most widely used to describe the relationships between the strain rate, flow stress, and temperature, especially at high temperatures [7]. It can accurately predict nonlinear histories under different conditions.

Mandal et al. [8] developed constitutive equation to predict the flow stress of a Ti-modified austenitic stainless steel. Cai et al. [9] developed constitutive equations for different phase regimes to study the workability of Ti6Al4 V alloy. Many other researchers developed artificial neural network models to predict flow stress during hot deformation [6]. 
Optimizing the processing parameters for the materials is also important. A processing map based on the dynamic material models is an effective method to control and optimize the processing parameters. Processing map technology was first proposed by Frost and Ashby [10] to optimize hot-working processing parameters and to control the microstructural evolution in the hot deformation of plain low-carbon steel. Subsequently, Prasad et al. [11] and Murty and Rao [12] made further modifications for this technology. In recent years, many researchers have successfully applied processing map technology to optimize the processing parameters of various metals, such as highstrength steels [13], austenitic stainless steels [14], Mg alloys [15], and Al alloys [16].

During a thermo-mechanical process, some microstructural evolutions, such as grain coarsening, phase transformation, precipitation, and recrystallization, can take place, all of which have an important effect on the processing parameters and mechanical properties of parts. Dynamic recrystallization (DRX) is a typical thermo-mechanical process that occurs in metals with medium or low stacking fault energy under certain deformation conditions. DRX can replace deformed microstructures with coarse or elongated grains by newly equiaxed recrystallized structures, which gives the material good mechanical properties [17]. Thus, it is important for engineers to control a microstructure by optimizing the processing parameters for promoting DRX. However, DRX is very sensitive to the processing parameters. It is necessary to clarify the DRX kinetics and microstructural evolution, which are beneficial to optimizing the processing parameters and controlling the microstructure. Many authors have therefore paid much attention to this subject. Chen et al. [18] investigated the DRX characteristics of $30 \mathrm{Cr} 2 \mathrm{Ni} 4 \mathrm{MoV}$ ultra-super-critical rotor steel during hot deformation. Najafizadeh and Jonas [19] proposed a theory to determine the critical conditions for DRX. Chen et al. [20] studied the DRX of superalloys by hot compression tests. They estimated the recrystallized volume fraction and grain size based on DRX models, and the results were compared with experimental values. Wei et al. [21], Liu et al. [22], and Zhu et al. [23] investigated the DRX behaviors of various metallic materials. Despite the large efforts invested in studies of the deformation behavior and DRX of various metallic materials, there is, however, little information available concerning the deformation behavior and DRX of the 10Ni5CrMoV steel. An investigation of this subject is therefore of necessity.

In this study, the deformation behavior of the $10 \mathrm{Ni} 5 \mathrm{CrMoV}$ steel was experimentally studied and an Arrhenius-type whole-process constitutive equation was developed. To validate the model, the predicted results were compared with the experimental data. To further study the deformation behavior, processing maps at different strains were established to explain the deformation mechanism. DRX of the material was studied using optical observation. The critical condition for the onset of DRX was determined, and its kinetics model was developed. To validate the model, the predicted results for DRX volume fraction and flow stress were compared with the experimental data.

\section{Experimental}

The chemical composition of $10 \mathrm{Ni} 5 \mathrm{CrMoV}$ steel was as follows: C 0.09 , Si $0.30, \mathrm{Mn} 0.50, \mathrm{Cr} 0.55, \mathrm{Ni} 4.55, \mathrm{Mo}$ 0.50 , V 0.05, Al 0.021, Co 0.1, S 0.002, P 0.005, H 0.147, $\mathrm{O} 0.0024, \mathrm{~N} 0.0073$, Fe balance. The initial grain size of the steel was $15 \mu \mathrm{m}$ (about 9.5 grain number). The cylinder specimens with the size of $15 \mathrm{~mm}$ in height and $10 \mathrm{~mm}$ in diameter were electro-discharged from the initial material to carry out the hot compression experiments. The temperature at which the austenite phase was transformed into the ferrite and pearlite phase was $820^{\circ} \mathrm{C}$.

The isothermal hot compression experiments were performed at a temperature range $800-1200{ }^{\circ} \mathrm{C}$, a strain rate range $0.01-10 \mathrm{~s}^{-1}$, and a height reduction of $60 \%$ on a Gleeble-3500 simulator. Prior to the deformation, the specimens were heated up to the austenized temperature $1250{ }^{\circ} \mathrm{C}$ for $5 \mathrm{~min}$ to completely dissolve the precipitates. After the austenization, the specimens were rapidly cooled at $10{ }^{\circ} \mathrm{C} \mathrm{s}^{-1}$ to the testing temperature and held for $5 \mathrm{~s}$ to ensure a uniform temperature distribution throughout the specimens. The deformation procedure is shown in Fig. 1. The deformation temperature was measured by a thermocouple that was spot-welded to the center of the specimen

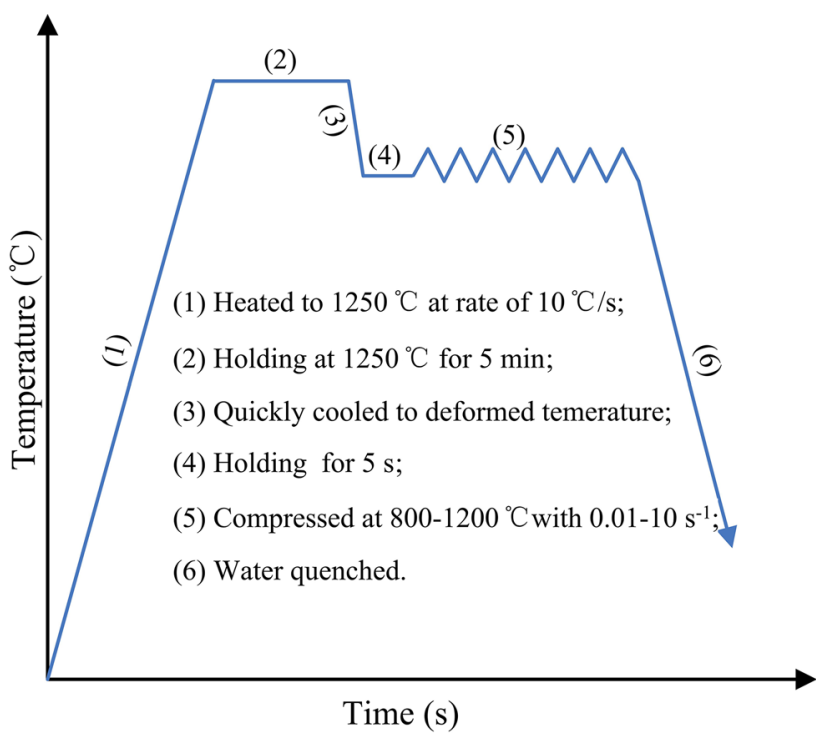

Fig. 1 Experimental procedure of hot compression test for acquiring stress strain data and microstructure 
surface. To reduce the die friction and ensure uniform deformation, two thin pieces of thallium were affixed to the flat dies. All of the compression tests were performed in an argon atmosphere. To preserve the microstructure at high temperatures, the compressed samples were water-quenched immediately after the compression test.

Following the hot compression experiments, the metallographic preparation of the specimens was carried out by cutting along their length axis, mechanically grinding using grit papers with different particle sizes, polishing and etching with a solution of $97 \%$ alcohol and $3 \%$ nitric acid for microstructural observation and with a solution of 5\% picric acid, $5 \%$ BSNa, $1 \%$ hydrogen peroxide and distilled water for grain size statistic. Then, the optical micrographs were taken in the center zone of the specimens using an OLYMPUS PMG3 optical microscope. Three to five micrographs at each deformation condition were used to estimate the average grain size and the recrystallization volume fraction. The average grain size was measured and evaluated using the linear intercept method according to the ASTME112-10 standard.

\section{Results and Discussion}

\subsection{Flow Behavior}

Typical stress-strain curves of the $10 \mathrm{Ni} 5 \mathrm{CrMoV}$ steel during hot compression under temperatures from 800 to $1200{ }^{\circ} \mathrm{C}$ and strain rates from 0.01 to $10 \mathrm{~s}^{-1}$ are shown in Fig. 2. The stress was very sensitive to strain, strain rate, and temperature. The stress increased significantly with increasing strain during the initial stage and then reached a plateau or peak value at high strains under different deformation conditions. Moreover, the stress increased with increasing strain rate at a given temperature and decreased with increasing temperature at a given strain rate.

Figure 2 shows that the stress-strain curves exhibited an obvious softening tendency under some conditions. The stress increased with strain to peak values, after which the stress decreased gradually until it reached a steady state. This phenomenon may be caused by microstructural evolution, such as DRX or dynamic recovery (DV). At the strain rate of $10 \mathrm{~s}^{-1}$, the stress increased with the strain. For stress that exhibited an obvious softening, a peak stress $\left(\sigma_{\mathrm{p}}\right)$ and its corresponding peak strain $\left(\varepsilon_{\mathrm{p}}\right)$ were easily found. These values are listed in Table 1 . It was clearly seen that $\sigma_{\mathrm{p}}$ increased with decreasing temperature at a given strain rate and decreased with decreasing strain rate at a given temperature. From Table 1, we could see that the $\varepsilon_{\mathrm{p}}$ moved toward a higher strain level with decreasing deformation temperature.
To further quantify the softening mechanism, the relationships of softening extent $\left(\eta=\Delta \sigma / \sigma_{\mathrm{p}}=\left(\sigma_{\mathrm{p}}-\sigma_{\mathrm{s}}\right) / \sigma_{\mathrm{p}}\right.$ $\times 100 \%$, where $\sigma_{\mathrm{s}}$ represents a stress at a steady stage) with temperature and strain rate are shown in Fig. $2 \mathrm{f}$, which showed that $\Delta \sigma$ was sensitive to both temperature and strain rate. The softening extent increased with increasing temperature regardless of strain rate. It implied that the volume fraction of DRX increased with temperature, which resulted in a larger softening in flow stress. Moreover, the strain rate influenced softening extent greatly. This value decreased from 27 to $15 \%$ when strain rate increasing from 0.01 to $1 \mathrm{~s}^{-1}$.

\subsection{Constitutive Model}

The deformation behavior of a material at high temperature can be described by an Arrhenius-type equation, which can give a good approximation among stress and strain, strain rate, and temperature [3]:

$\dot{\varepsilon}=A F(\sigma) \exp \left(-\frac{Q}{R T}\right)$,

$F(\sigma)=\left\{\begin{array}{l}A_{1}(\sigma)^{n_{1}}(\alpha \sigma<0.8) \\ \exp \left(\beta_{1} \sigma\right)(\alpha \sigma>1.2) \\ {[\sinh (\alpha \sigma)]^{n}(\text { for all } \sigma)}\end{array}\right.$,

where $\dot{\varepsilon}$ is the strain rate $\left(\mathrm{s}^{-1}\right), R$ is the universal gas constant $\left(8.31 \mathrm{~J} \mathrm{~mol}^{-1} \mathrm{~K}^{-1}\right), T$ is the absolute temperature $(\mathrm{K}), Q$ is the activation energy for deformation $\left(\mathrm{kJ} \mathrm{mol}^{-1}\right)$, and $\sigma$ is the flow stress (MPa) for a given strain. $A, A_{1}, \alpha$, $\beta_{1}, n$, and $n_{1}$ are material constants.

For all value of $\sigma$, the constitutive equation is written as:

$\dot{\varepsilon}=A[\sinh (\alpha \sigma)]^{n} \exp \left(-\frac{Q}{R T}\right)$.

Taking the logarithm of both sides of Eq. (1) at the $\sigma_{\mathrm{p}}$, the following formula can be obtained:

$\ln \dot{\varepsilon}=n_{1} \ln \sigma+\ln A A_{1}-\frac{Q}{R T}(\alpha \sigma<0.8)$,

and

$\ln \dot{\varepsilon}=\beta_{1} \sigma_{p}+\ln A-\frac{Q}{R T}(\alpha \sigma>1.2)$.

According to Eqs. (4) and (5), the variations of flow stress $\sigma_{\mathrm{p}}$ with strain rate on a logarithm scale are shown in Fig. $3 \mathrm{a}$ and $\mathrm{b}$ to determine the values of $n_{1}$ and $\beta_{1}$, respectively.

Figure $3 \mathrm{a}$ and $\mathrm{b}$ shows that the fitting lines were nearly parallel to each other; thus, the values of $n_{1}$ and $\beta_{1}$ were averaged to 7.63 and 0.10 , respectively. According to the relation of $\alpha=\beta_{1} / n_{1}$, the value of $\alpha$ was taken as 0.013 . It was assumed that the value of $Q$ was independent of 

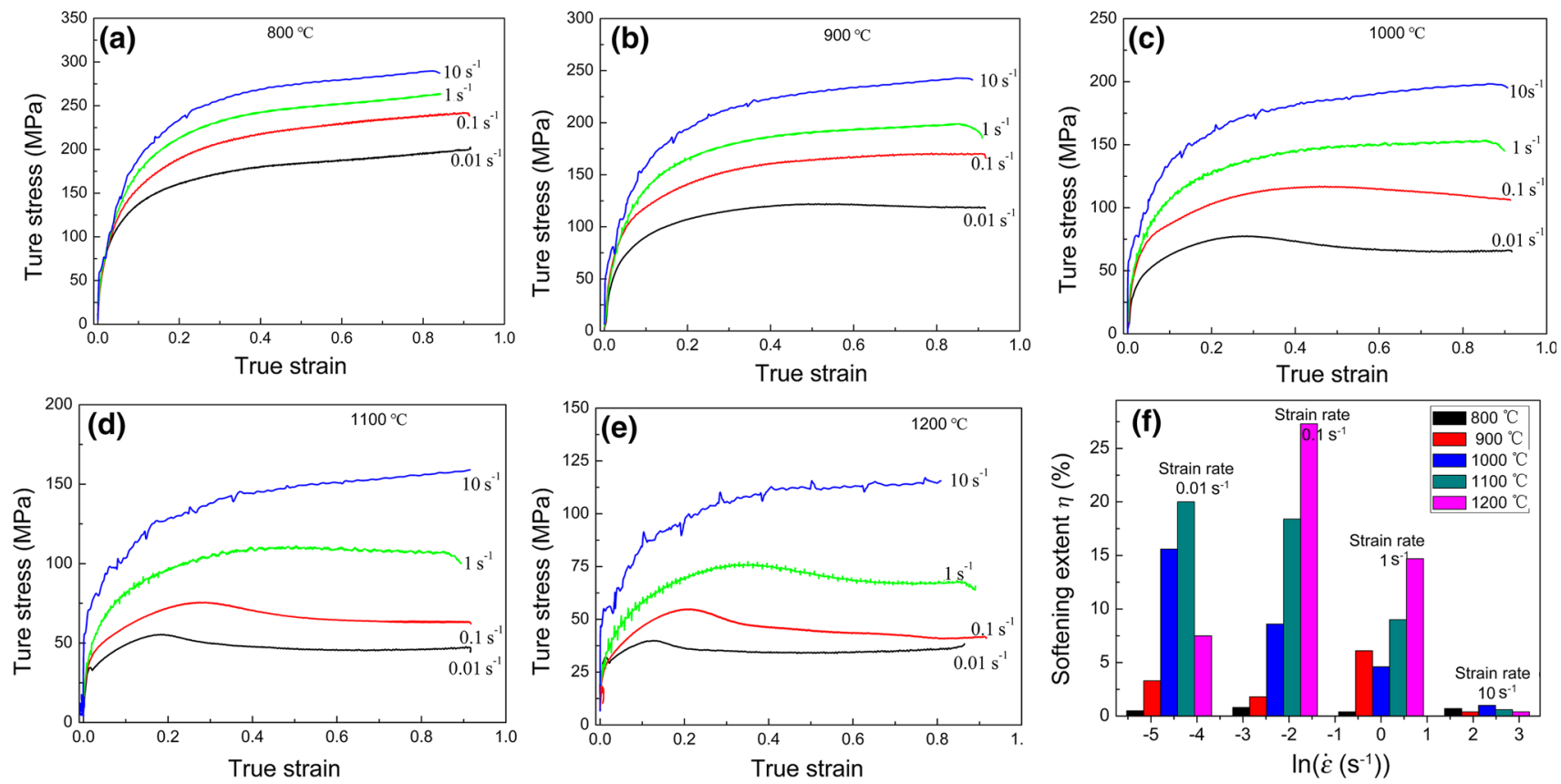

Fig. 2 Stress-strain curves of steel at strain rates from 0.01 to $10 \mathrm{~s}^{-1}$ and temperatures of $\mathbf{a} 800{ }^{\circ} \mathrm{C}, \mathbf{b} 900{ }^{\circ} \mathrm{C}, \mathbf{c} 1000{ }^{\circ} \mathrm{C}, \mathbf{d} 1100{ }^{\circ} \mathrm{C}, \mathbf{e} 1200{ }^{\circ} \mathrm{C}$, f softening extent

Table 1 Peak stresses and peak strains $\left(\sigma_{\mathrm{p}} / \varepsilon_{\mathrm{p}}\right)$ at different conditions

\begin{tabular}{lrrrl}
\hline Temperature $\left({ }^{\circ} \mathrm{C}\right)$ & \multicolumn{1}{c}{$0.01 \mathrm{~s}^{-1}$} & \multicolumn{1}{c}{$0.1 \mathrm{~s}^{-1}$} & $1 \mathrm{~s}^{-1}$ & $10 \mathrm{~s}^{-1}$ \\
\hline 900 & $121.0 / 0.44$ & $169.0 / 0.69$ & $197.0 / 0.77$ & - \\
1000 & $76.4 / 0.22$ & $116.0 / 0.43$ & $152.0 / 0.71$ & - \\
1100 & $55.0 / 0.17$ & $75.6 / 0.29$ & $110.0 / 0.40$ & - \\
1200 & $40.0 / 0.12$ & $55.0 / 0.20$ & $75.0 / 0.33$ & - \\
\hline
\end{tabular}

temperature, so taking the logarithm of both sides of Eq. (3), it can be rewritten as:

$\ln \dot{\varepsilon}=n \ln [\sinh (\alpha \sigma)]+\ln A-Q /(R T)$.

According to Eq. (6), the relationships among $\ln \dot{\varepsilon}$ and $\ln [\sinh (\alpha \sigma)], \ln [\sinh (\alpha \sigma)]$ and $1 / T$ are plotted in Figs. 4 and 5 , respectively.

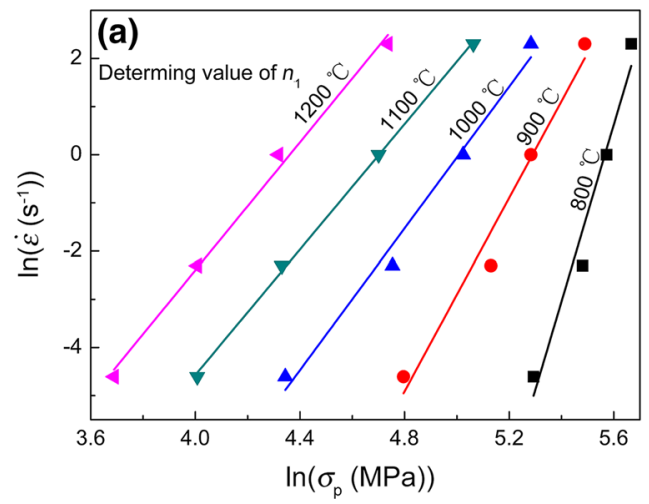

The value of $n$ at different temperatures in Eq. (6) was determined by the slope of each fitted line in Fig. 6. The values of $n$ were estimated to be $5.7,4.3,4.0,4.2$, and 5.1 at temperatures of $800,900,1000,1100$, and $1200{ }^{\circ} \mathrm{C}$, respectively. The value of $n$ varied slightly with temperature. The average value of $n$ in Eq. (7) was 4.66. Similarly, the value of $Q /(n R)$ was determined by the slopes of the fitting lines in Fig. 5. The slopes of the fitting lines varied slightly from 9.3 to 10.3 as the strain rate ranged from 0.01 to $10 \mathrm{~s}^{-1}$. Thus, the average value of $Q$ was taken as $450 \mathrm{~kJ} \mathrm{~mol}^{-1}$. The value of $A$ was $2.06 \times 10^{15}$. Thus, the constitutive equation at peak strain can be written as:

$\dot{\varepsilon}=2.06 \times 10^{15}[\sinh (0.01336 \sigma)]^{4.66} \exp \left(-\frac{450,000}{R T}\right)$.

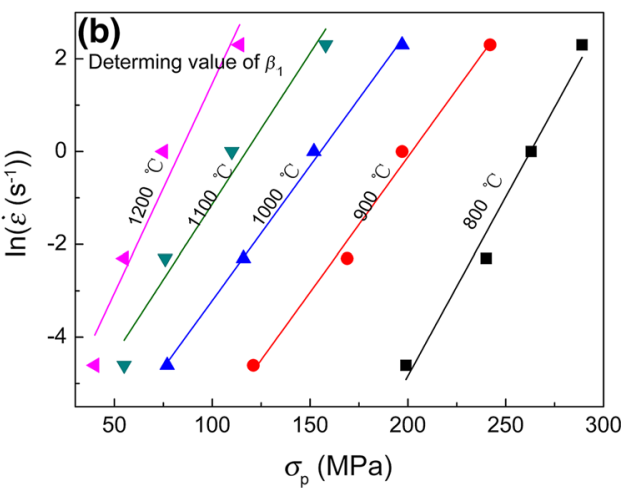

Fig. 3 Determining values of $n_{1}$ (a) and $\beta_{1}$ (b) from Eqs. (2) and (3) 


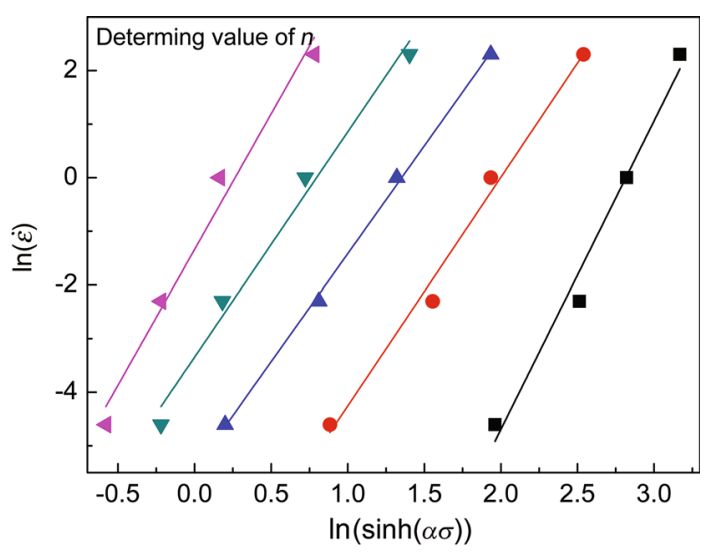

Fig. 4 Determining value of $n$ from Eq. (6)

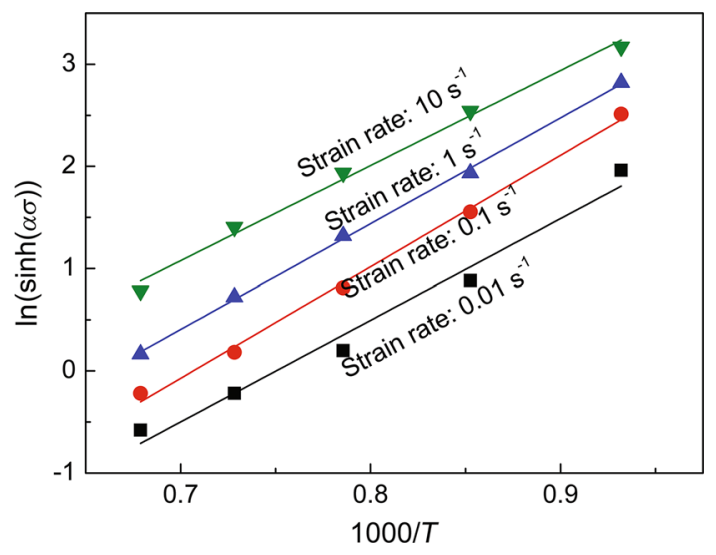

Fig. 5 Determining value of $Q$ from Eq. (6)

\subsection{Predicting Flow Stress}

The material constants in Eq. (3) were expressed as a function of strain, as depicted in Fig. 6. According to Eq. (3), the following formula can be obtained:

$\left(\frac{Z}{A}\right)^{\frac{1}{n}}=\sinh (\alpha \sigma)=\frac{\mathrm{e}^{\alpha \sigma}-\mathrm{e}^{-\alpha \sigma}}{2}$,

where $Z$ represents the Zener-Hollomon parameter $(\dot{\varepsilon} \exp (Q /(R T)))$. By solving Eq. (8), the following formula can be obtained:

$\mathrm{e}^{\alpha \sigma}=\left(\frac{Z}{A}\right)^{\frac{1}{n}}+\left(\left(\frac{Z}{A}\right)^{\frac{2}{n}}+1\right)^{\frac{1}{2}}$.

Taking the logarithm of both sides of Eq. (9), the flow stress $\sigma$ can be written as:

$\sigma=\frac{1}{\alpha} \ln \left(\left(\frac{Z}{A}\right)^{\frac{1}{n}}+\left(\left(\frac{Z}{A}\right)^{\frac{2}{n}}+1\right)^{\frac{1}{2}}\right)$.
By substituting the material constant functions (depicted in Fig. 6) into Eq. (10), the constitutive equation of the material for the entire strain range was obtained. Thus, the stress can be predicted, as shown in Fig. 7. The predicted stress matched well with the tested values, i.e., the predicted data increased with increasing strain rate and decreasing temperature.

To further evaluate the constitutive equation, standard statistical parameters, such as the correlation coefficient $r$ and average absolute relative error (AARE), were employed, respectively, defined as [11]:

$r=\frac{\sum_{i=1}^{N}\left[\left(E_{i}-\bar{E}\right)\left(P_{i}-\bar{P}\right)\right]}{\sqrt{\sum_{i=1}^{N}\left(E_{i}-\bar{E}\right)^{2} \sum_{i=1}^{N}\left(P_{i}-\bar{P}\right)^{2}}}$,

$\operatorname{AARE}(\%)=\frac{1}{N} \sum_{i=1}^{N}\left|\frac{E_{i}-P_{i}}{E_{i}}\right| \times 100$

where $E$ represents the experimental data value and $P$ is the corresponding predicted value, $\bar{E}$ and $\bar{P}$ are the average values of $E$ and $P$, respectively, and $N$ is the total number of data points. Figure 8 shows the correlation between the experimental and predicted values. A good correlation was obtained, i.e., the value of $r$ was 0.977 , while the largest AARE was $5.7 \%$. This indicated that the constitutive equation was reliable and had good ability to predict the flow stress.

\subsection{Processing Map}

The processing map has been developed based on the dynamic material model, and it has been widely used to study the hot formability of metallic materials in the past years. The workpiece undergoing the hot deformation is considered to be a dissipater of power. An instantaneous power $P_{1}$ dissipated can be separated into two terms: $G$ associated with the plastic deformation and $J$ related to microstructural evolution. It is given by [24]:

$P_{1}=\sigma \dot{\varepsilon}=G+J=\int_{0}^{\dot{\varepsilon}} \sigma \mathrm{d} \dot{\varepsilon}+\int_{0}^{\sigma} \dot{\varepsilon} \mathrm{d} \sigma$.

The strain rate sensitivity $(m)$ of flow stress is the factor that partitions power between deformation heat and microstructural evolution [25]. The processing map consists of two parameters, namely efficiency of the power dissipation $\eta$ and flow instability $\xi$. The $\eta$ is defined as a function of temperature and strain rate given by:

$\eta=\frac{J}{J_{\max }}=\frac{2 m}{m+1}$,

where $m$ is the strain rate sensitivity, which is defined as: 

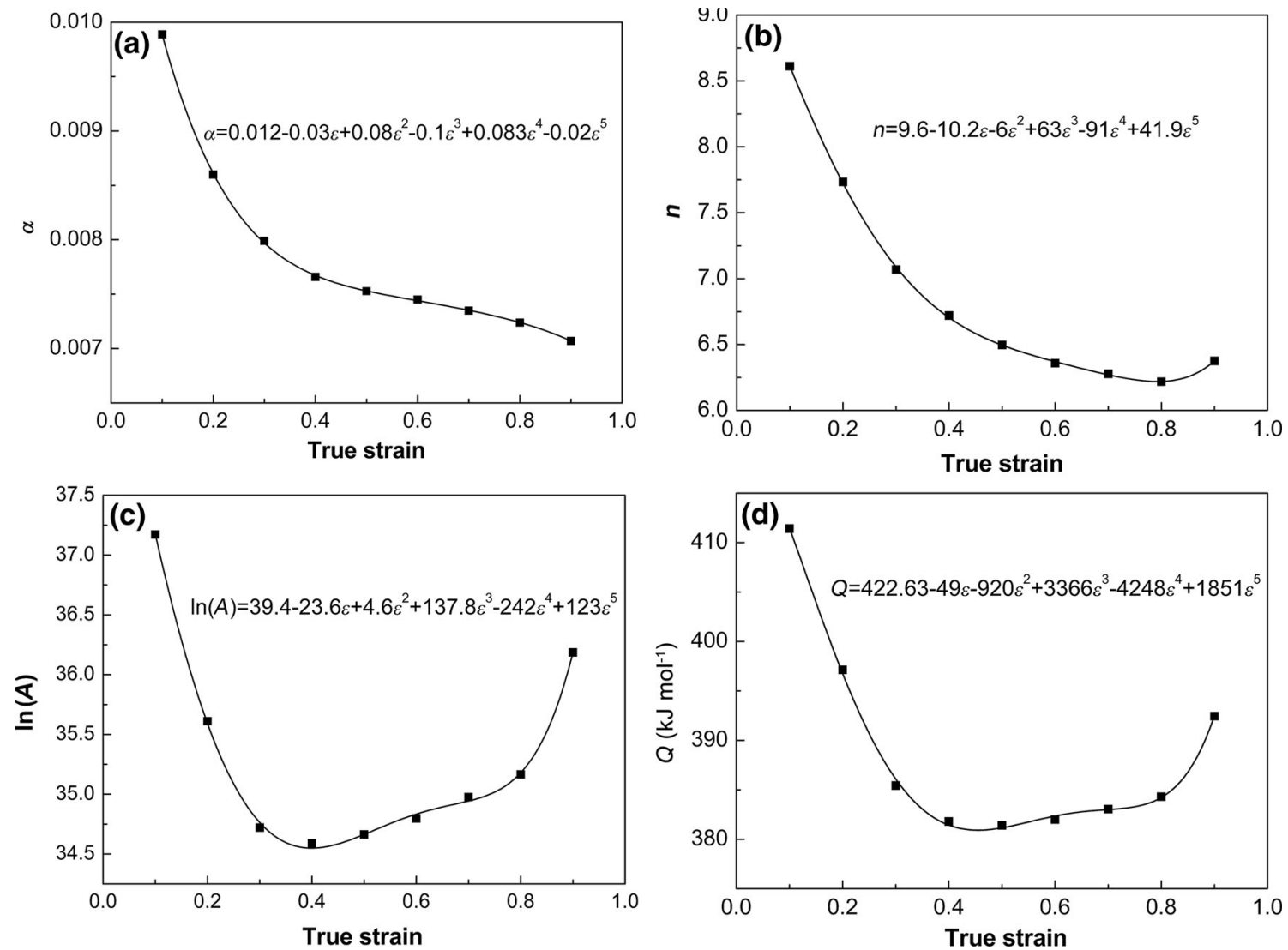

Fig. 6 Variation of material constants in Eq. (3) with strain: a $\alpha ; \mathbf{b} n ; \mathbf{c} A ; \mathbf{d} Q$
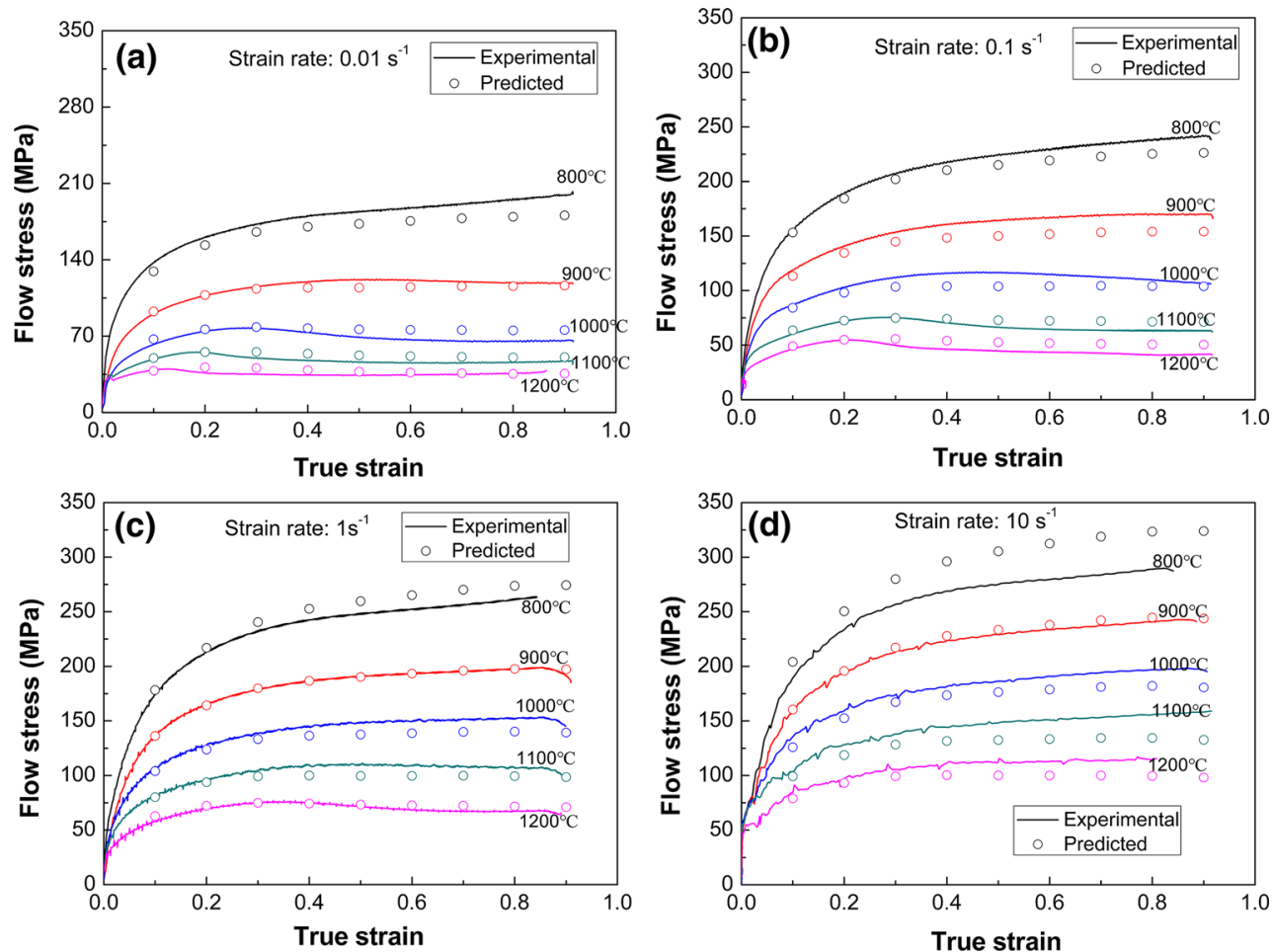

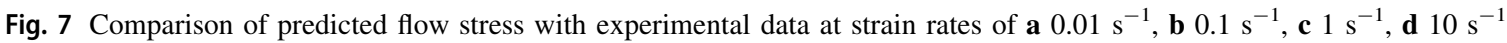




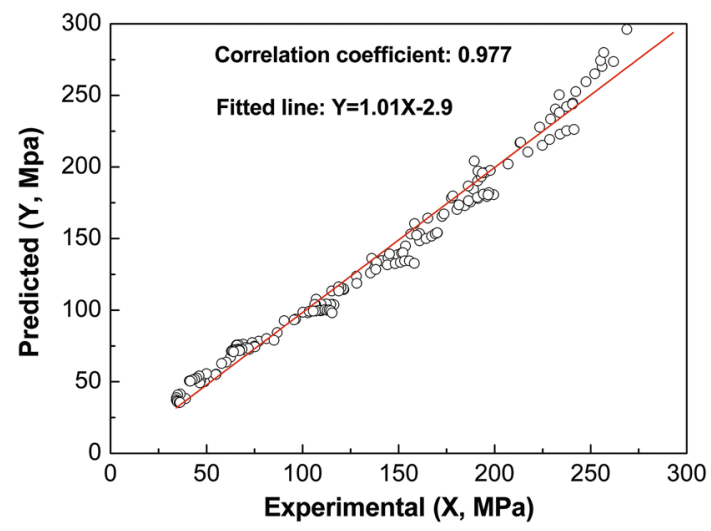

Fig. 8 Correlation between experimental and predicted values

$m=\left(\frac{\partial \ln \sigma}{\partial \ln \dot{\varepsilon}}\right)_{T, \dot{\varepsilon}}$

The variation of $\eta$ with temperature and strain rate represents a power dissipation map which is usually considered as an iso-efficiency contour map. A criterion for the onset of flow instability can be given by [26]:

$\xi=\frac{\partial \ln \left(\frac{m}{m+1}\right)}{\partial \ln (\dot{\varepsilon})}+m<0$.

The negative value represents a regime of instability. A superimposition of the instability map on the power dissipation map gives a processing map. By the processing map, safe regions with efficiency contours converging toward a peak efficiency and unsafe regions with $\xi$ less than zero can be identified. For the safe regions, the intrinsic workability of the material is good and such as DRX or superplasticity may occur. While for the unsafe regions, flow instability may occur, i.e., adiabatic shear bands or flow localization. Therefore, an appropriate temperature-strain rate processing window for the hot working can be found. The processing maps for the material at different strains are shown in Fig. 9.

In Fig. 9, the contour numbers represented the power dissipation efficiency and the shaded domains indicated the unsafe regions of flow instability (negative $\xi$ ). At a strain of 0.2 (Fig. 9a), there was a small shaded domain at low temperature and high strain rate, while the maximum power dissipation efficiency reached 0.28 . This indicated that flow instability may not occur under these conditions, which may result from the lower plastic deformation that could not produce defects such as adiabatic shear bands or localized plastic flow. As the deformation continued (Fig. 9b), the strain increased to 0.4 , the shaded region began to expand, and flow instability may occur. With further strain to 0.8 , the maximum $\eta$ reached 0.46 and was located in the domain at higher temperatures (1100-1200 ${ }^{\circ} \mathrm{C}$ ) and lower strain rates (near $0.001 \mathrm{~s}^{-1}$ ). Under these conditions, the microstructures had obviously changed. The typical microstructural evolution was DRX. This phenomenon was validated by the following factors. The original grain size was refined, the grain boundaries became curved, and many new equiaxed grains appeared along original boundaries, as shown in Fig. 10 .

\subsection{Microstructural Evolution}

\subsubsection{Dynamic Recrystallization}

Figure 11 shows the microstructural evolution of the material at different conditions. The effects of temperature and strain rate were significant. The original grains were elongated perpendicular to the compression direction at $800{ }^{\circ} \mathrm{C}$ (Fig. 11a-c). With the increase in temperature, elongated grains were gradually replaced by equiaxed grains. Typical DRX also took place. The new recrystallized grains preferably formed around the original grain boundaries. This was mainly because the zones around grain boundaries had many defects with high deformation energy; thus, nucleation occurred easily and more recrystallized grains appeared in these zones.

The recrystallized grain size and volume fraction of recrystallization $\left(f_{\mathrm{drx}}\right)$ were sensitive to the strain rate and temperature. These values increased with increasing temperature and decreasing strain rate; for example, the recrystallized grain size and the volume fraction at $1200{ }^{\circ} \mathrm{C}$ decreased from 100 to $35 \mu \mathrm{m}$, and from nearly $100-80 \%$, respectively, when the strain rate increased from 0.01 to $1 \mathrm{~s}^{-1}$; at a strain rate of $0.01 \mathrm{~s}^{-1}$, these values increased from 5 to $100 \mu \mathrm{m}$, and from 5 to $100 \%$, respectively, when the temperature increased from 800 to $1200{ }^{\circ} \mathrm{C}$.

The variation of recrystallized grain size with temperature and strain rate can be explained by the following reasons. It is known that the size is determined by the migration mobility of the grain boundary ( $v=M P$, where $v$ is migration rate, $M$ is migration mobility, and $P$ is the driving force), with the driving force $P$ provided by the difference in dislocation density and growth time. Under the same strain rate, the migration mobility increases with temperature, while the driving force decreases. However, the reduction in the driving force is smaller than the increase in migration mobility; therefore, the growth velocity increases with temperature. At a given temperature, although the driving force of a recrystallized grain increases with increasing strain rate, the growth time is largely reduced. Therefore, the recrystallized grain size decreased with increasing strain rate.

\subsubsection{Critical Condition for Onset of Dynamic Recrystallization}

The stress-strain curves of the material exhibited an obvious softening trend, which mainly resulted from DRX. 

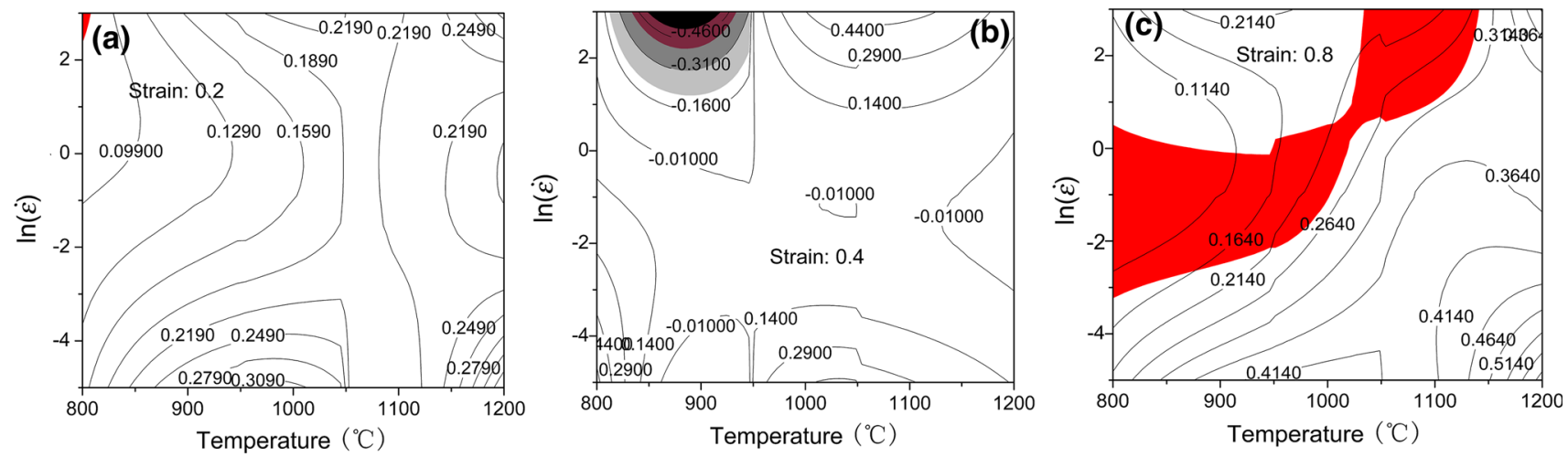

Fig. 9 Processing maps of steel deformed at different strains of a 0.2, b 0.4, $\mathbf{c} 0.8$
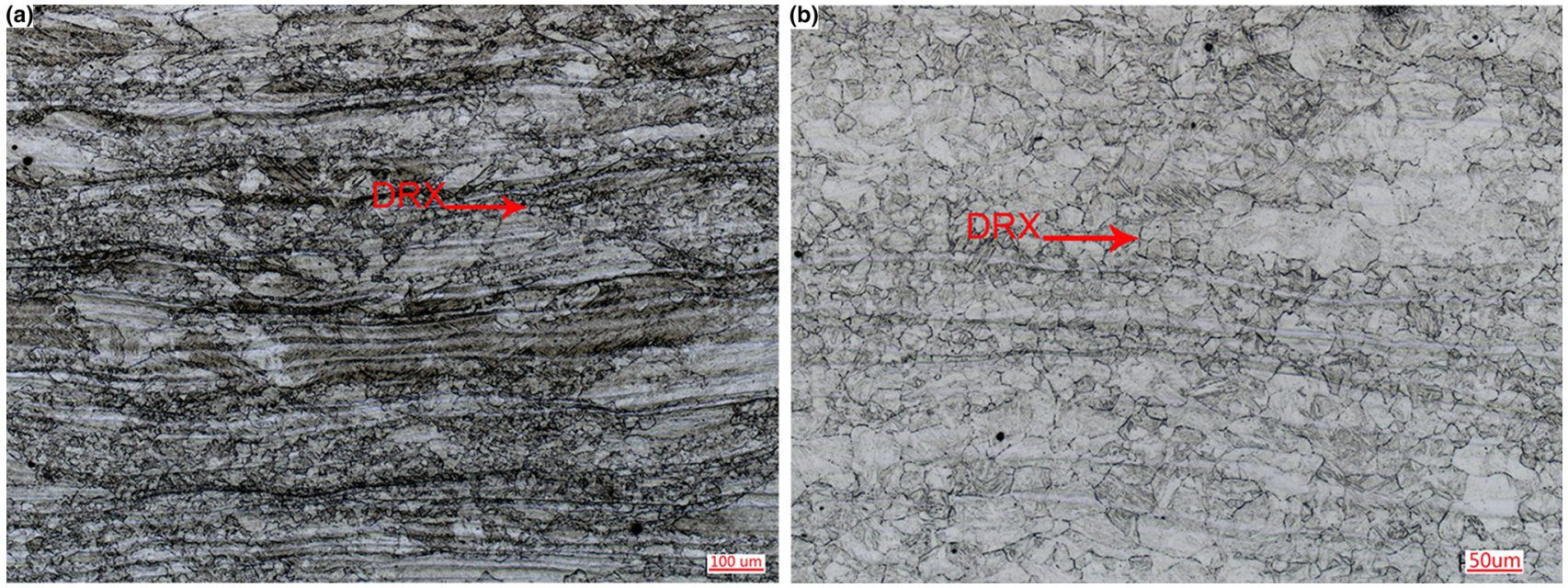

Fig. 10 Typical microstructures of steel showing DRX deformed at strain rate of $0.1 \mathrm{~s}^{-1}$ and higher temperatures of a $950{ }^{\circ} \mathrm{C}, \mathbf{b} 1000{ }^{\circ} \mathrm{C}$

The onset of DRX can therefore be determined by these curves. However, DRX usually initiates at a critical condition (strain or stress) before the peak value. The critical condition depends on the basic chemical composition and thermo-mechanical parameters of the material. Many researchers have proposed various mathematics models to predict the critical condition. Based on the static recrystallization nucleation mechanism, Barnett et al. [27] developed a model to identify a particular strain as the critical condition for the initiation of DRX, while Gottstein et al. [28] identified the critical strain based on a dislocation work-hardening model. Poliak and Jonas [26] believed that the critical strain for the initiation of DRX can be directly identified from the inflections in curves of $(-\partial \theta / \partial \sigma)-\sigma$, where $\theta$ represents the work-hardening rate $(\theta=\partial \sigma / \partial \varepsilon$, where $\sigma$ is stress and $\varepsilon$ is strain). Najafizadeh and Jonas [19] subsequently simplified the model of Poliak and Jonas and proposed a method to fit the strain-hardening data to a third-order polynomial to determine the critical condition. Recently, Chen et al. [18] concluded that considering the work-hardening rate as a function of stress was the best method to determine the critical condition for the onset of DRX. In this work, we adopted this method to determine the critical condition. The curves of $\theta-\sigma$ were fitted to a third-order polynomial expressed as:

$\theta=B_{0}+B_{1} \sigma+B_{2} \sigma^{2}+B_{3} \sigma^{3}$,

where $B_{0}$ to $B_{3}$ are material constants. To determine the inflection point in the curves, the second derivative of Eq. (17) with respect to $\sigma$ was taken, expressed as:

$\frac{\mathrm{d}^{2} \theta}{\mathrm{d} \sigma^{2}}=2 B_{2}+6 B_{3} \sigma$.

Setting Eq. (18) equal to zero, the value corresponds to the critical stress for the initiation of DRX. Thus,

$2 B_{2}+6 B_{3} \sigma=0$ and $\sigma_{\mathrm{c}}=-\frac{B_{2}}{3 B_{3}}$,

where $\sigma_{\mathrm{c}}$ is the critical stress. After determining $\sigma_{\mathrm{c}}$, the corresponding critical strain $\left(\varepsilon_{\mathrm{c}}\right)$ can be identified from the stress-strain curves. Figure $12 \mathrm{a}-\mathrm{c}$ shows the third-order fitting curves of $\theta-\sigma$. The fitted curves matched the 

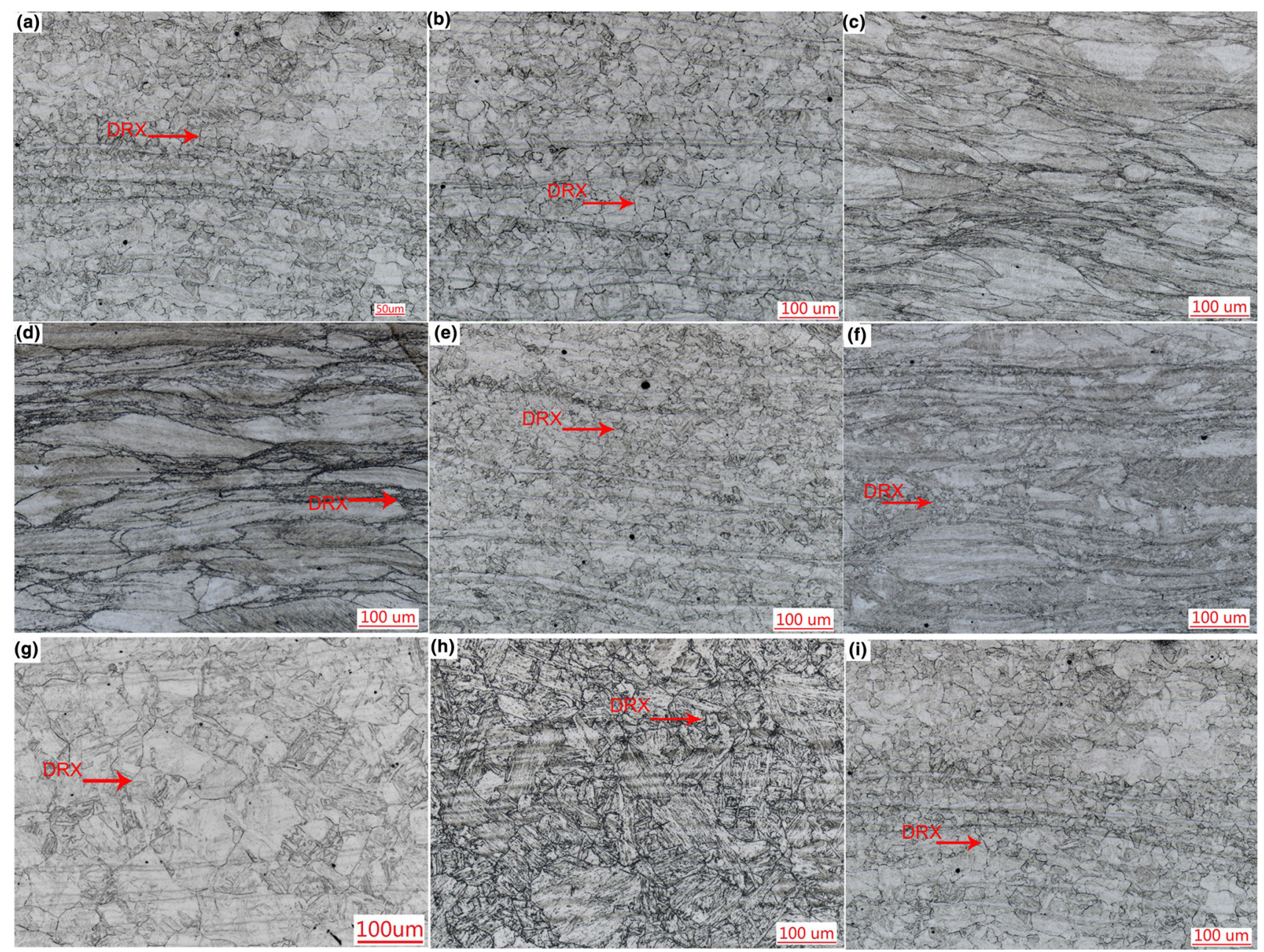

Fig. 11 Microstructural evolution of steel at temperatures of $\mathbf{a}-\mathbf{c} 800{ }^{\circ} \mathrm{C}, \mathbf{d}-\mathbf{f} 1000{ }^{\circ} \mathrm{C}, \mathbf{g}-\mathbf{i} 1200{ }^{\circ} \mathrm{C}$ and strain rates of $\mathbf{a}, \mathbf{d}, \mathbf{g ~} 0.01 \mathrm{~s}^{-1}, \mathbf{b}, \mathbf{e}$, h $0.1 \mathrm{~s}^{-1}, \mathbf{c}, \mathbf{f}, \mathbf{i} 1 \mathrm{~s}^{-1}$

experimental data well. According to Eq. (19), $\sigma_{\mathrm{c}}$ was obtained from the derivative of the fitted third-order polynomials. Figure $12 \mathrm{~d}-\mathrm{f}$ shows the relations of $(-\partial \theta / \partial \sigma)-\sigma$, which were used to determine the critical stress. The corresponding $\varepsilon_{\mathrm{c}}$ was determined from the stress-strain curves. The values of critical stress $\sigma_{\mathrm{c}}$ and critical strain $\varepsilon_{\mathrm{c}}$ are listed in Table 2 .

\subsubsection{Dynamic Recrystallization Kinetics}

DRX is a typical thermally activated process that takes place via nucleation and subsequent growth. It is generally accepted that only when strain reaches the critical value can nucleation occur. With increasing strain, the recrystallized nuclei begin to grow by grain boundary migration. The nucleation and growth process can be considered to represent the kinetics of DRX. The basic characteristic of DRX kinetics displays a sigmoidal form with respect to time. This means that an initial incubation period is followed by a rate of change that is initially slow, then accelerates, and, finally, becomes slow again as the process is completed. DRX kinetics at a constant strain rate can be expressed as [18]:

$f_{\mathrm{drx}}=1-\exp \left[-\beta_{\mathrm{d}}\left(\frac{\varepsilon-\varepsilon_{\mathrm{c}}}{\varepsilon_{0.5}}\right)^{k_{3}}\right]\left(\varepsilon>\varepsilon_{\mathrm{c}}\right)$

where $f_{\mathrm{drx}}$ is the DRX volume fraction, $\beta_{\mathrm{d}}$ and $k_{3}$ are the material constants, $\varepsilon$ and $\varepsilon_{\mathrm{c}}$ are the strain and critical strain, respectively. $\varepsilon_{0.5}$ is the strain to $50 \%$ DRX volume fraction, which is written as:

$\varepsilon_{0.5}=k_{1} \dot{\varepsilon}^{k_{2}} \exp \left(\frac{Q_{\mathrm{drx}}}{R T}\right)$

where $k_{1}$ and $k_{2}$ are material constants and $Q_{\mathrm{drx}}$ is the activation energy for DRX $\left(\mathrm{kJ} \mathrm{mol}^{-1}\right)$. The value of $f_{\mathrm{drx}}$ can be determined by either quantitative metallographic measurement or from a flow-curve analysis. Flow-curve analysis is a simpler and quicker method, because 

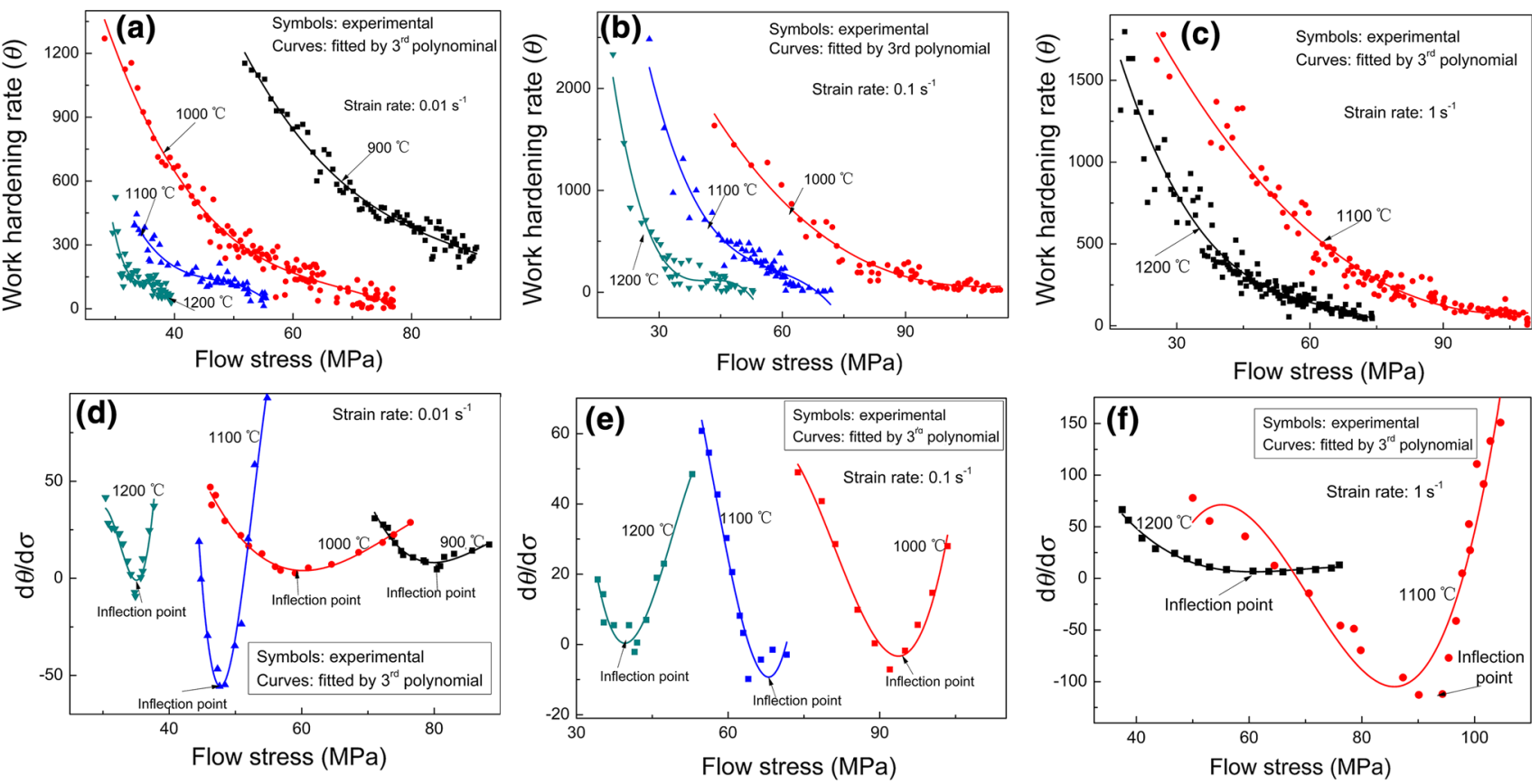

Fig. 12 Curves of $\theta-\sigma(\mathbf{a}-\mathbf{c})$ and $(-\partial \theta / \partial \sigma)-\sigma(\mathbf{d}-\mathbf{f})$ at strain rates of $\mathbf{a}, \mathbf{d} 0.01 \mathrm{~s}^{-1}, \mathbf{b}, \mathbf{e}^{0.1} \mathrm{~s}^{-1}, \mathbf{c}, \mathbf{f} 1 \mathrm{~s}^{-1}$

Table 2 Values of critical strain and stress $\left(\sigma_{\mathrm{c}} / \varepsilon_{\mathrm{c}}\right)$ under different deformation conditions

\begin{tabular}{lllll}
\hline Temperature $\left({ }^{\circ} \mathrm{C}\right)$ & $0.01 \mathrm{~s}^{-1}$ & $0.1 \mathrm{~s}^{-1}$ & $1 \mathrm{~s}^{-1}$ & $10 \mathrm{~s}^{-1}$ \\
\hline 900 & $80.0 / 0.07$ & - & - & - \\
1000 & $60.1 / 0.10$ & $93.5 / 0.14$ & - & - \\
1100 & $47.8 / 0.09$ & $63.0 / 0.11$ & $94.6 / 0.20$ & - \\
1200 & $34.8 / 0.06$ & $40.0 / 0.06$ & $66.0 / 0.16$ & - \\
\hline
\end{tabular}

quantitative metallographic measurement needs a large quantity of samples to be examined and it is difficult to precisely ascertain the new grains [13]. The method for determining $f_{\text {drx }}$ by analyzing the flow stress curves is illustrated in Fig. 13. In this study, we adopted the following expression to determine $f_{\mathrm{drx}}$ :

$f_{\mathrm{drx}}=\frac{\Delta \sigma_{\mathrm{s}}}{\sigma_{\mathrm{sat}}-\sigma_{\mathrm{ss}}}$

where $\Delta \sigma_{\mathrm{s}}$ is considered as the net softening effect directly attributable to DRX. This is expressed as:

$\Delta \sigma_{\mathrm{s}}=\sigma_{\mathrm{sat}}-\sigma$

where $\sigma_{\text {sat }}$ denotes the flow stress and its softening effect that only results from dynamic recovery (without DRX softening). $\sigma_{\mathrm{ss}}$ is the steady-state stress under the DRX conditions.

According to Eq. (22), the value of $f_{\mathrm{drx}}$ can be determined from the stress-strain curves. The method to calculate the values of $\sigma_{\text {sat }}$ and $\sigma_{\text {ss }}$ can be found in Ref. [29].

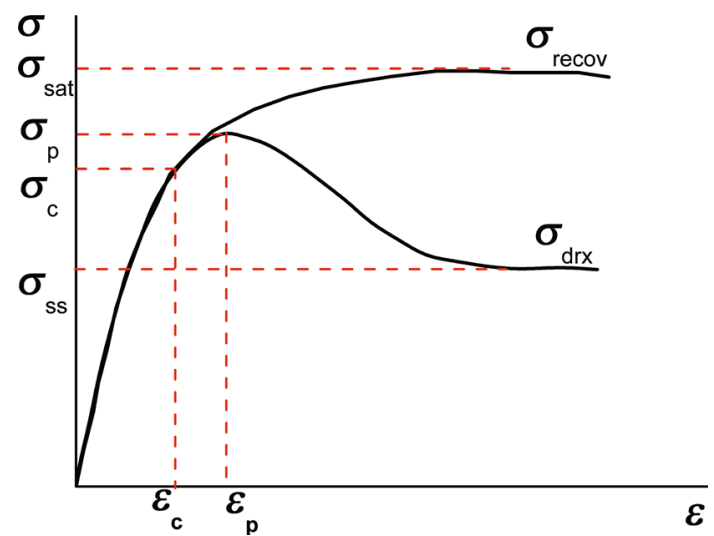

Fig. 13 Method to determine volume fraction of DRX through net softening effect

The value of $f_{\text {drx }}$ determined by Eq. (22) is shown in Fig. 14. $f_{\text {drx }}$ showed a sigmoidal form with respect to time and was very sensitive to temperature and strain rate. With a decrease in temperature or increase in strain rate, the value of $f_{\mathrm{drx}}$ became smaller, while the incubation period became longer.

To determine the material constants in Eq. (20), the logarithms of both sides of Eq. (21) were taken:

$\ln \varepsilon_{0.5}=\ln k_{1}+k_{2} \dot{\varepsilon}+\frac{Q_{\mathrm{drx}}}{R T}$.

Thus, by linear regression of Eq. (24), the values of $k_{2}$ and $Q_{\mathrm{drx}}$ can be taken as 0.2 and $65,373.38 \mathrm{~J} \mathrm{~mol}^{-1}$, respectively, as displayed in Fig. 15a and b. Substituting these values into Eq. (24) gave a value of $k_{1}$ of 0.002 . 

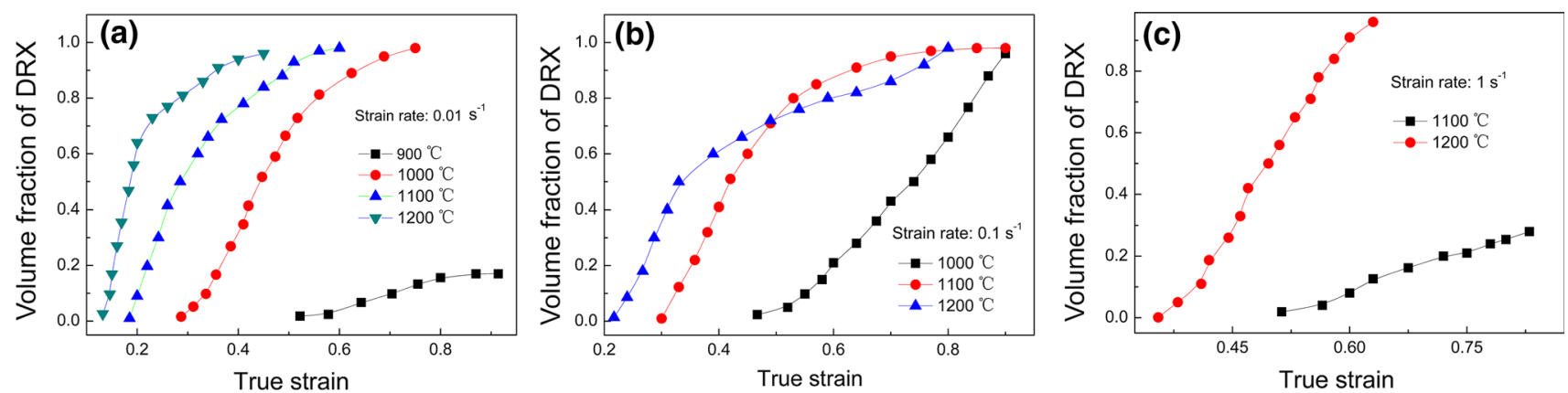

Fig. 14 DRX kinetics at strain rates of $\mathbf{a} 0.01 \mathrm{~s}^{-1}, \mathbf{b} 0.1 \mathrm{~s}^{-1}, \mathbf{c} 1 \mathrm{~s}^{-1}$

Similarly, taking the logarithmic form of Eq. (20), we can obtain:

$\ln \left(-\ln \left(1-f_{\mathrm{drx}}\right)\right)=\ln \beta_{\mathrm{d}}+k_{3} \ln \left(\frac{\varepsilon-\varepsilon_{\mathrm{c}}}{\varepsilon_{0.5}}\right)$.

The relationship between $\ln \left(-\ln \left(1-f_{\mathrm{drx}}\right)\right)$ and $\ln \left[\left(\varepsilon-\varepsilon_{\mathrm{c}}\right) / \varepsilon_{0.5}\right]$ is depicted in Fig. 15c. The values of $k_{3}$ and $\beta_{\mathrm{d}}$ were obtained by linear regression as 2.43 and 1.07, respectively. Finally, the kinetics equation of DRX can be expressed as:

$f_{\mathrm{drx}}=1-\exp \left[-1.07\left(\frac{\varepsilon-\varepsilon_{\mathrm{c}}}{\varepsilon_{0.5}}\right)^{2.43}\right]\left(\varepsilon>\varepsilon_{\mathrm{c}}\right)$.
To validate the DRX kinetics, the predicted $f_{\mathrm{drx}}$ was compared with the experimental data, as shown in Fig. 16. The trend predicted by Eq. (26) exhibited obvious sigmoidal characteristics, which was similar to that of the experimental data. The predicted values increased with increasing temperature and decreasing strain. During the initial stages, the predicted data increased slowly with strain, but grew rapidly until a steady stage, when the DRX was nearly complete.

To further validate the kinetics model, the flow stress can be modified as [29]:

$\sigma=\left(1-f_{\mathrm{drx}}\right) \sigma_{\mathrm{sat}}+f_{\mathrm{drx}} \sigma_{\mathrm{ss}}$.
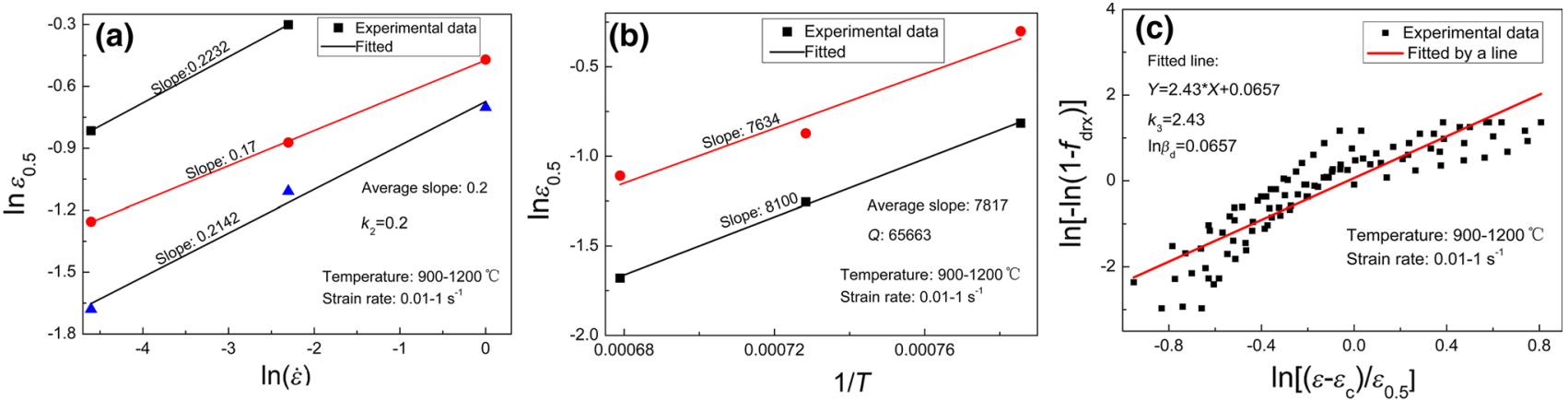

Fig. 15 Determining values of $\mathbf{a} k_{1}, \mathbf{b} k_{2}, \mathbf{c} \beta_{\mathrm{d}}$ and $k_{3}$
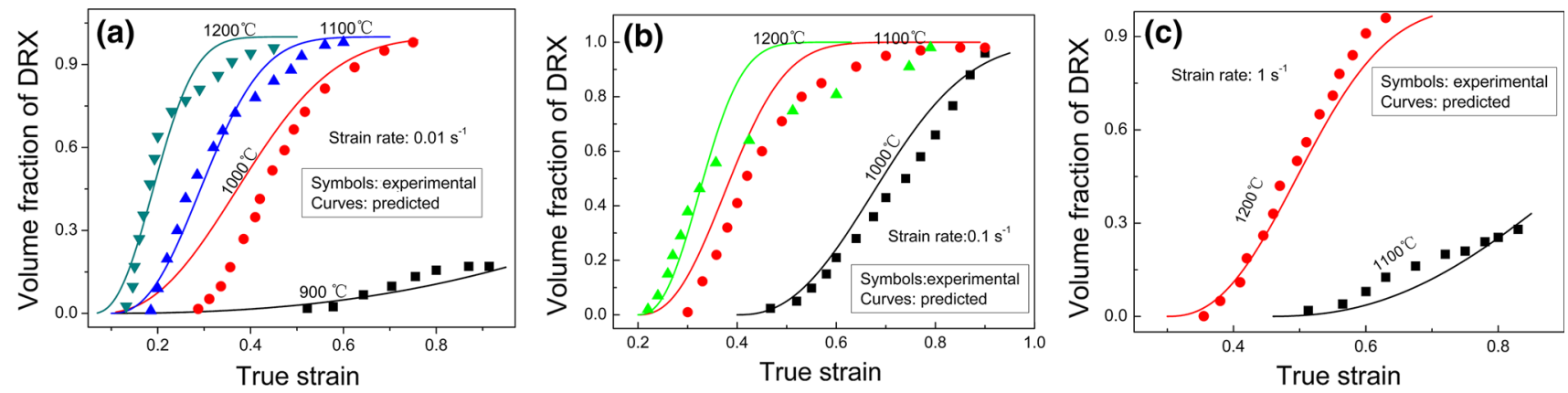

Fig. 16 Comparison of predicted value with experimental data at strain rates of a $0.01 \mathrm{~s}^{-1}, \mathbf{b} 0.1 \mathrm{~s}^{-1}, \mathrm{c}^{1} \mathrm{~s}^{-1}$ 

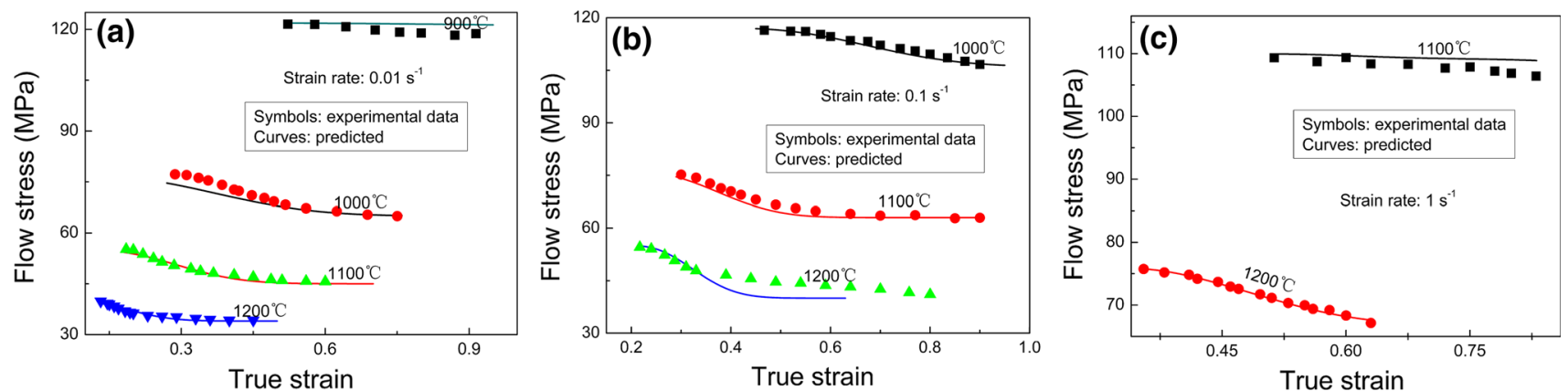

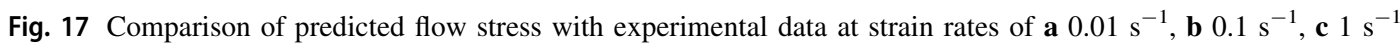

The flow stress predicted by Eq. (27) is shown in Fig. 17. The predicted values agreed well with the experimental data.

\section{Conclusions}

(1) The deformation behavior and DRX of $10 \mathrm{Ni} 5 \mathrm{Cr}-$ $\mathrm{MoV}$ steel were experimentally investigated. A reliable Arrhenius-type constitutive model was established. To validate the model, the predicted flow stress was compared with the experimental values: the correlation coefficient and the largest relative error were 0.977 and $5.7 \%$, respectively.

(2) Processing maps at strains of $0.2,0.4$, and 0.8 were constructed, which were used to identify the processing conditions where flow instability occurred.

(3) The critical strain for the onset of DRX was identified. A DRX kinetics model was developed that had good ability to predict the recrystallization volume fraction.

Acknowledgements This work was supported financially by the Scientific Research Foundation of Tianjin University of Technology and Education (No. KYQD1801) and the National Natural Science Foundation of Tianjin City (No. 13JCYBJC38900). The authors also thank Kathryn Sole, Ph.D., from Liwen Bianji, Edanz Group China (www.liwenbianji.cn/ac), for editing the English text of a draft of this manuscript.

\section{References}

[1] S.K. Rajput, G.P. Chaudhari, S.K. Nath, J. Mater. Process. Technol. 237, 113 (2016)

[2] Q. Wang, X.S. Liu, P. Wang, X. Xiong, H.Y. Fang, J. Mater. Process. Technol. 240, 77 (2017)

[3] Y.C. Lin, X.M. Chen, Mater. Des. 32, 1733 (2011)

[4] Y.C. Lin, F.Q. Nong, X.M. Chen, D.D. Chen, M.S. Chen, Vacuum 137, 104 (2017)
[5] D.D. Chen, Y.C. Lin, Y. Zhou, M.S. Chen, D.X. Wen, J. Alloys Compd. 708, 938 (2017)

[6] D.G. He, Y.C. Lin, M.S. Chen, J. Chen, D.X. Wen, X.M. Chen, J. Alloys Compd. 649, 1075 (2015)

[7] Y.C. Huang, Y.C. Lin, J. Deng, G. Liu, M.S. Chen, Mater. Des. 53, 349 (2014)

[8] S. Mandal, V. Rakesh, P.V. Sivaorasad, S. Venugopal, K.V. Kasiviswanathan, Mater. Sci. Eng., A 500, 114 (2009)

[9] J. Cai, F.G. Li, T.Y. Liu, B. Chen, M. He, Mater. Des. 32, 1144 (2011)

[10] H.J. Frost, M.F. Ashby, Deformation-Mechanism Maps: The Plasticity and Creep of Metals and Ceramics (Pergamon Press, London, 1982), pp. 45-56

[11] Y.V.R.K. Prasad, H.L. Gegel, S.M. Doraivelu, J.C. Malas, J.T. Morgan, K.A. Lark, D.R. Barker, Metall. Trans. A 15, 1883 (1984)

[12] S.V.S.N. Murty, B.N. Rao, Mater. Sci. Lett. 17, 1203 (1998)

[13] A. Mohamadizadeh, A.Z. Hanzaki, H.R. Abedi, S. Mehtonen, D. Porter, Mater. Charact. 107, 293 (2015)

[14] S. Wang, L.G. Hou, J.R. Luo, J.S. Zhang, L.Z. Zhuang, J. Mater. Process. Technol. 225, 110 (2015)

[15] H.Z. Li, H.J. Wang, X.P. Liang, H.T. Liu, Y. Liu, X.M. Zhang, Mater. Sci. Eng., A 528, 1548 (2011)

[16] D.X. Wen, Y.C. Lin, H.B. Li, X.M. Chen, J. Deng, L.T. Li, Mater. Sci. Eng., A 591, 183 (2014)

[17] X. Ma, C.W. Zheng, X.G. Zhang, D.Z. Li, Acta Metall. Sin. (Engl. Lett.) 29, 1127 (2016)

[18] F. Chen, Z.S. Cui, S.J. Chen, Mater. Sci. Eng., A 528, 5073 (2011)

[19] A. Najafizadeh, J. Jonas, ISIJ Int. 46, 1679 (2006)

[20] X.M. Chen, Y.C. Lin, D.X. Wen, J.L. Zhang, M. He, Mater. Des. 57, 568 (2014)

[21] H.L. Wei, G.Q. Liu, H.T. Zhao, M.H. Zhang, Mater. Sci. Eng., A 596, 112 (2014)

[22] Y.G. Liu, M.Q. Li, J. Luo, Mater. Sci. Eng., A 574, 1 (2013)

[23] S.L. Zhu, H.Z. Cao, J.S. Ye, W.H. Hu, G.Q. Zheng, J. Iron. Steel Res. Int. 22, 264 (2015)

[24] S. Anbuselvan, S. Ramanathan, Mater. Des. 31, 2319 (2010)

[25] Y.V.R.K. Prasad, K.P. Rao, Mater. Sci. Eng., A 487, 316 (2008)

[26] E.I. Poliak, J.J. Jonas, Acta Mater. 44, 127 (1996)

[27] M.R. Barnett, G.L. Kelly, P.D. Hodgson, Metall. Mater. Trans. A 33, 1892 (2002)

[28] G. Gottstein, M. Frommert, M. Goerdeler, N. Schafer, Mater. Sci. Eng., A 387-389, 604 (2004)

[29] H.Q. Liang, H.Z. Guo, Y.Q. Ning, X.N. Peng, C. Qin, Z.F. Shi, Y. Nan, Mater. Des. 63, 798 (2014) 